\title{
Osteoporosis, diabetes, and hypertension are major risk factors for mortality in older adults: an intermediate report on a prospective survey of 1467 community- dwelling elderly healthy pensioners in Switzerland
}

Jean-Pierre Gutzwiller ${ }^{1,5^{*}}$, Jean-Pierre Richterich', Zeno Stanga ${ }^{2,6}$, Urs E. Nydegger ${ }^{3}$, Lorenz Risch ${ }^{3,7}$ and Martin Risch ${ }^{4}$

\begin{abstract}
Background: Osteoporosis is an important morbidity factor for ageing populations in developed countries. However, compared to the amount of information available on diabetes and cardiovascular disease, little is known about the direct impact of osteoporosis on general mortality in older age.

Methods: We obtained data from a prospective population-based cohort of pensioners from the SENIORLAB study who were subjectively healthy. The inclusion criteria were an age of at least 60 years and Swiss residence. We assessed and analysed clinical measures, voluntary reports, and laboratory values.

Results: In total, 1467 subjects were included in the cohort. The mean follow-up time was 3.68 years (95\% confidence interval, 3.64-3.71). The ages of the included participants ranged from 60 to 99 years. At follow-up, there were 1401 survivors, and 66 participants had died. According to the multivariate analysis (Cox regression), osteoporosis was the most important risk factor for all-cause mortality (hazard ratio, 4.46; 95\% confidence interval, 1.82-10.91), followed by diabetes (hazard ratio, 2.17; 95\% confidence interval, 1.04-4.52) and hypertension (hazard ratio, 1.81; 95\% confidence interval, 1.09-3.03).

Conclusions: Osteoporosis is a major risk factor for all-cause mortality in a subjectively healthy senior population, followed by type 2 diabetes mellitus and hypertension. Osteoporosis should be more actively diagnosed in healthy pensioners before they develop osteoporosis-associated health incidents.

Trial registration: The present study was registered in the International Standard Randomized Controlled Trial Number registry: ISRCTN53778569.
\end{abstract}

Keywords: Osteoporosis, Mortality, Diabetes, Hypertension, Pensioners

\footnotetext{
* Correspondence: dr.gutzwiller@magendarm-thalwil.ch

${ }^{1}$ Magendarm Thalwil AG, Zürcherstrasse 61, CH-8800 Thalwil, Switzerland

${ }^{5}$ University of Basel, Klingelbergstrasse 61, 4056 Basel, Switzerland

Full list of author information is available at the end of the article
}

(c) The Author(s). 2018 Open Access This article is distributed under the terms of the Creative Commons Attribution 4.0 International License (http://creativecommons.org/licenses/by/4.0/), which permits unrestricted use, distribution, and reproduction in any medium, provided you give appropriate credit to the original author(s) and the source, provide a link to the Creative Commons license, and indicate if changes were made. The Creative Commons Public Domain Dedication waiver (http://creativecommons.org/publicdomain/zero/1.0/) applies to the data made available in this article, unless otherwise stated. 


\section{Background}

In developed countries, the number of seniors over 60 years of age has grown over the last century. In Switzerland, the proportion of adolescents in relation to the total population fell from $40.7 \%$ in 1900 to $20.2 \%$ in 2014 and was accompanied by a rise in the proportion of pensioners (aged over 64 years) from $5.8 \%$ (1900) to $17.8 \%$ (2014). This rate is expected to increase to $26 \%$ by 2045 [1]. In addition, the generation over 64 years of age has become wealthier in recent decades, and an estimated $80 \%$ of homeowners are above 65 years of age [2].

The aging generation is in better health than in the past. The Swiss Federal Statistical Office maintains mortality statistics; these data include the prevalence of multimorbid terminal phases, among which one nosological entity is assigned as the cause of death [1]. Currently, little is known about the risk factors for mortality in the older generation. The best evidence is from the Cardiovascular Health Study, which was published in 1998 [3]. That study demonstrated that arteriosclerosis (i.e., aortic stenosis and stenosis of the internal carotid artery) was a principal risk factor for mortality, accounting for a twoto fivefold excess mortality risk. The report found that systolic hypertension (over $169 \mathrm{mmHg}$, a 2.4-fold excess mortality risk), use of diuretics, renal failure, and diabetes with fasting glucose $>7.2 \mathrm{mmol} / \mathrm{L}$ (approximately twofold) were less important factors. That study also identified both age and smoking as minor risk factors. Cancer was not mentioned as a mortality factor in that cohort [3]. In addition, that investigation did not include osteoporosis, which is generally considered an important factor in morbidity and mortality in older adults $[4,5]$. One report found a slightly higher mortality risk for osteoporosis than the expected general mortality risk. However, that study did not compare the risk of mortality from osteoporosis with other risk factors with respect to general health status [6]. Other studies have reported slightly higher (between 1.2 and 1.5) relative risks of mortality associated with an osteoporosis diagnosis [7-9], with the exception of one study from Japan that actually showed a higher mortality risk [10].

Studies investigating osteoporosis typically focus on fractures and the subsequent diagnosis of osteoporosis. Data on clinically asymptomatic individuals diagnosed with osteoporosis are scarce, although some studies are cited above.

Today, osteoporosis is known to be a disease of the elderly. However, the epidemiological frequency is underestimated, and its prevalence in some places, such as in Switzerland, is unknown. Another example of this underestimation is the treatment gap. In Switzerland, estimates suggest that between 36 and $58 \%$ of diagnosed cases of osteoporosis are not treated as recommended by the guidelines [11]. Epidemiological data from Sweden estimate that osteoporosis affects approximately $7.8 \%$ of men and $27.9 \%$ of women among citizens aged 70-74 years [12]. In Europe, the prevalence of osteoporosis is estimated to be between 5.9 and $7.2 \%$ in men and 19.1 and $23.5 \%$ in women [12].

One of the aims of the present prospective cohort study was to evaluate general health-impairing conditions in subjectively healthy retired people in Switzerland. This study also aimed to explore under-evaluated potential risk factors for mortality in this age group and to compare the magnitudes of their effects.

\section{Methods}

\section{Aim, design and study setting}

The present study involved a population-based prospective cohort. The study was conducted within the framework of the SENIORLAB [13] study (DOI https://doi. org/10.1186/ISRCTN 53778569). The primary aim of that study was to establish reference intervals for several laboratory parameters in an elderly cohort (www.seniorlabor.ch).

\section{Characteristics of the participants}

The study consecutively enrolled subjectively healthy elderly volunteers from February 2009 to July 2012 and has been described in detail elsewhere $[14,15]$. Potentially eligible participants were contacted via newspaper advertisements, various associations with high proportions of healthy elderly members (e.g., alpine and sports clubs), and personal contacts of the study collaborators. The inclusion criteria were as follows: at least 60 years of age, residence in Switzerland, and subjects describing themselves as healthy. Prior to study entry, the participants completed a questionnaire (Fig. 1). Subjectively healthy elderly were defined as seniors or pensioners who lived at home and could independently manage their daily lives without clinical signs of disease.

The present study did not apply any additional exclusion criteria to those used previously. We collected the subjects' personal histories, anthropometric measurements (body weight, height, and body mass index [BMI]), and a fasting venous blood sample that was collected into S-Monovette tubes (Sarstedt, Sevelen, Switzerland). Consistent with standard regional habits in Switzerland, the food intake of the participants consisted of an approximate daily energy consumption per person of $2661 \mathrm{kcal}(11,135 \mathrm{~kJ})$, including $14 \%$ protein, $51 \%$ carbohydrate, and $35 \%$ fat. None of the participants was alcohol dependent. The participants were informed of selected results from their laboratory tests that were relevant for healthy seniors (i.e., their glucose, haemoglobin A1c (HbA1c), and creatinine levels). The risk of participation was considered very low with respect to the risk of phlebotomy of a peripheral vein 


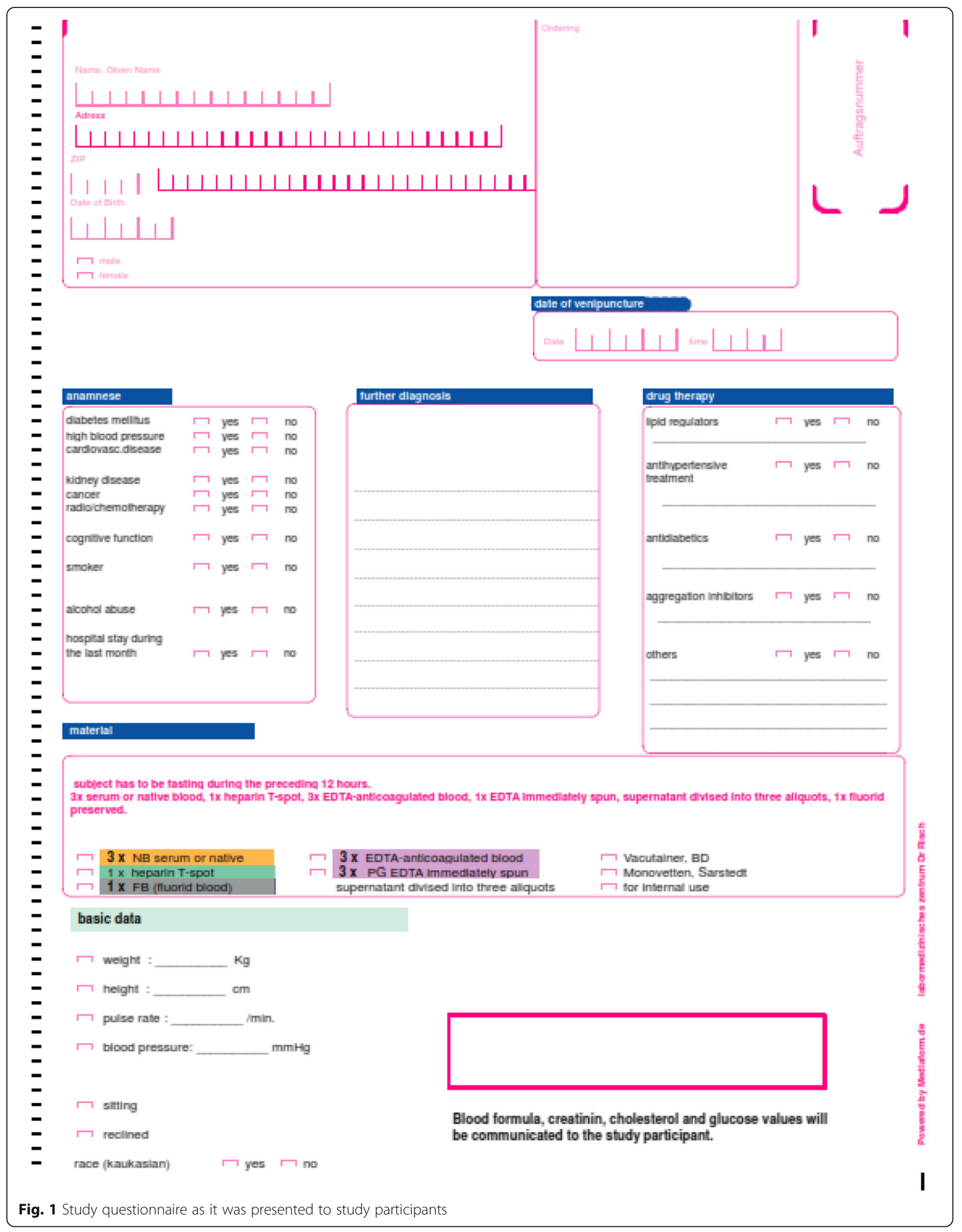


(usually in the cubital region), which under Swiss ethics is classified as category A. The exclusion criteria were candidates who had overt type 2 diabetes mellitus (T2DM) or missing fasting plasma glucose (FPG) or HbA1c values.

Follow-up at the intercurrent end points of the study was conducted by directly contacting the study participants or their relatives or caregivers. Collection of death rates was conducted on behalf of the public authorities. The follow up visits ended in December 2014. The details of the SENIORLAB study have recently been published [16]. Importantly, co-morbidities obtained at baseline were included in the analysis.

\section{Data collection}

At the baseline visit, subject's histories and vital data such as height, weight and BMI were taken. The questionnaire given to the participants is presented in Fig. 1. In Addition, systolic and diastolic blood pressure was recorded in a sitting position after a 10-min rest. Venous blood was drawn into S-Monovette tubes after overnight fasting. Blood samples were processed (centrifuged, aliquoted, and analysed or frozen at $-80{ }^{\circ} \mathrm{C}$ ) immediately to enable standardized preanalytics. A follow-up interview collected information on subjective well-being and survival. A negative response to the question of whether the patient was feeling healthy was defined to have unhealthy conditions, which was related to morbidity.

For the follow-up interview, the study subjects were contacted by mail and telephone. In cases with no response, official communal authorities, relatives, or neighbours were contacted. All diagnoses were obtained using good medical practices in doctor's offices or by medical hospital staff. Where possible, osteoporosis was diagnosed using osteodensitometry.

Laboratory parameters were measured using various analytic platforms. We employed commercially available materials to guarantee quality control. The highly sensitive C-reactive protein, retinol-binding protein, $\alpha 1$-acid glycoprotein, and haptoglobin levels were determined using the Siemens ProSpec (Siemens, Zurich, Switzerland). The HbA1c level was measured using high-performance liquid chromatography (Bio-Rad D-10; Pratteln, Switzerland). Total cholesterol, low-density lipoprotein cholesterol, high-density lipoprotein cholesterol, blood urea nitrogen, uric acid, lipase, pancreatic amylase, prealbumin, and transferrin were determined on the Cobas Integra 800 (Roche Diagnostics Rotkreuz Switzerland). Measurements of brain natriuretic peptide and thyroid-stimulating hormone were obtained using the Architect 14000 instrument (Abbott, Baar, Switzerland). Parathyroid hormone and $\beta 2-$ microglobulin were assayed using the Immulite 2000 analyser (Diagnostics Products Corporation, Bühlmann Laboratories, Allschwil, Switzerland).
The isotope dilution mass spectrometry-standardized serum creatinine concentration was determined using a modified Jaffe method on the Cobas Integra 800 instrument. The inter-day coefficients of variation for creatinine were $4.27 \%$ at $42 \mu \mathrm{mol} / \mathrm{L}$ and $1.96 \%$ at $556 \mu \mathrm{mol} / \mathrm{L}$.

The datasets used and/or analysed during the current study are available from the corresponding author upon reasonable request.

\section{Ethics}

This study was performed in accordance with the ethical guidelines of the 1957 Declaration of Helsinki, and informed consent was received from all participants. Ethical approval for the present study was obtained from the Cantonal Ethics Committee of Bern (KEK Bern, Study Nr 166/08), Bern, Switzerland.

\section{Statistical analysis}

The data analyses were done using the statistical software package Stata, version 6.0 for Windows (Stata Corp., 2000, College Station, TX, USA). Values are reported as the means \pm standard errors of the mean. Differences were considered significant at $P<0.05$.

The mean follow-up time for the entire cohort was 3.68 years. A flow chart of the study is shown in Fig. 2.

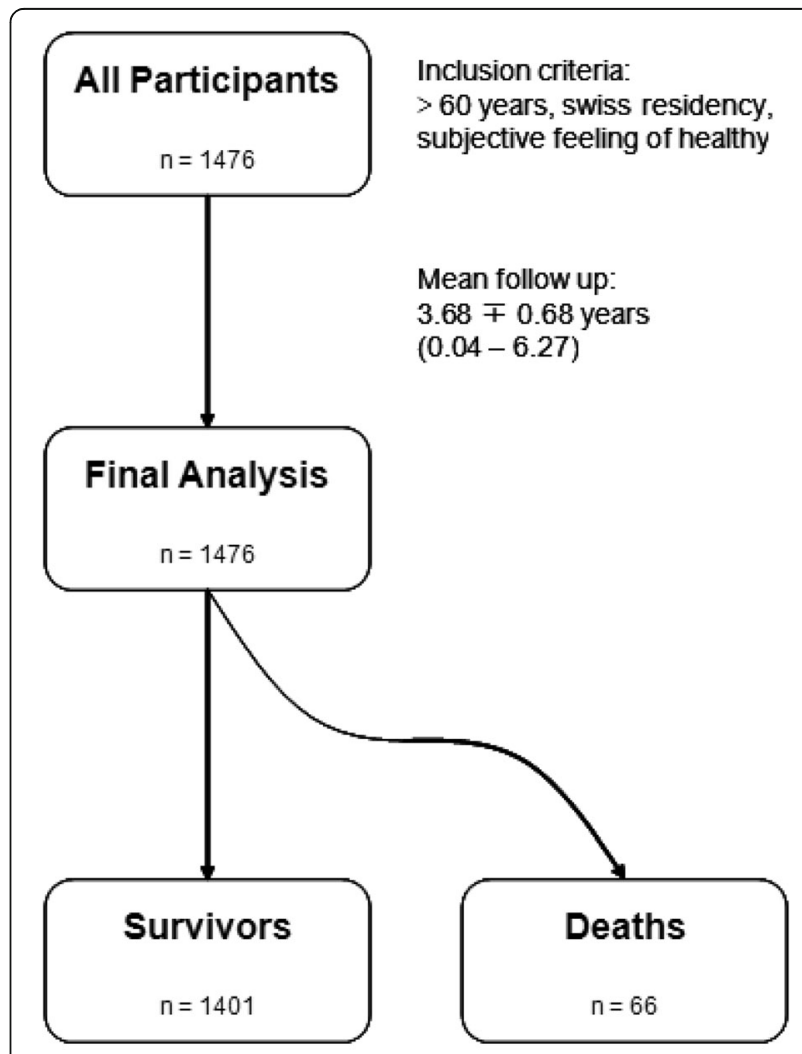

Note: nobody was lost to follow up

Fig. 2 Presentation of study flow chart 
We analysed possible predictors, such as smoking, sex, cancer, cerebrovascular disease, heart disease, T2DM, and osteoporosis, using Cox regression analysis with and without covariates (Cox proportional hazards model), the Chi-square test, and Fisher's exact test. Multivariate and Cox regression analyses with covariates were performed to assess the association of different possible risk factors detected by bivariate analysis and were incorporated into the final statistical model. Confounding variables were included if they changed the risk estimates by $>10 \%$.

The Kaplan-Meier method was used for the survival analysis.

\section{Results}

\section{Subject characteristics}

The characteristics of the cohort are shown in Tables 1 and 2. In total, 1467 subjects were included in the cohort. The mean follow-up time was 3.68 years (95\% confidence interval $[\mathrm{CI}], 3.64-3.71$ ), and the median follow-up time was 3.83 years. The tables for women and men are provided separately. The ages of the participants ranged from 60 to 99 years. The ratio of men to women in the population was 1:1.16. The mean BMI was $25.5 \mathrm{~kg} / \mathrm{m}^{2}$. The prevalence of osteoporosis in our cohort was $0.4 \%$ in men and $6.4 \%$ in women. Significant differences were found for weight, BMI, smoking status, type 2 diabetes, hypertension and osteoporosis. No significant differences were observed for age, cerebrovascular disease, cancer or death.

\section{Bivariate analysis}

As of 2014, diabetic pensioners had a higher mortality risk than non-diabetics (hazard ratio [HR], 2.79; 95\% CI, $1.38-5.66 ; P=0.001$ ). Participants previously diagnosed with osteoporosis had a higher mortality risk

Table 1 Demographic characteristics of the SENIORLAB study: Men

\begin{tabular}{lllll}
\hline Variable & Subjects & Mean, (\%) & STD & Min; Max \\
\hline age [years] & 680 & 71.7 & \pm 7.6 & $60 ; 96$ \\
weight $[\mathrm{kg}]$ & 679 & 79.5 & \pm 12.0 & $50 ; 176$ \\
BMI $\left[\mathrm{kg} / \mathrm{m}^{2}\right.$ ] & 678 & 26.1 & \pm 3.6 & $18.6 ; 56.8$ \\
Follow-up [years] & 680 & 3.60 & \pm 0.77 & $0.04 ; 6.27$ \\
Smoker & 63 & 9.3 & & \\
Alcohol abuse & 6 & 0.9 & & \\
Typ 2 diabetes mellitus & 52 & 7.6 & & \\
Hypertension & 285 & 41.9 & & \\
CVD & 115 & 16.9 & & \\
Osteoporosis & 3 & 0.4 & & \\
Cancer & 48 & 7.1 & & \\
Deaths & 37 & 5.4 & & \\
\hline
\end{tabular}

Table 2 Demographic characteristics of the SENIORLAB study: Women

\begin{tabular}{lllll}
\hline Variable & Subjects & Mean, (\%) & STD & Min; Max \\
\hline age [years] & 787 & 72.4 & \pm 8.1 & $60 ; 99$ \\
weight $[\mathrm{kg}]$ & 787 & 65.7 & \pm 11.1 & $36 ; 121$ \\
BMI $\left[\mathrm{kg} / \mathrm{m}^{2}\right]$ & 785 & 24.9 & \pm 4.0 & $14.4 ; 42.9$ \\
Follow-up [years] & 787 & 3.74 & \pm 0.58 & $0.06 ; 5.05$ \\
Smoker & 37 & 4.7 & & \\
Alcohol abuse & 0 & - & & \\
Typ 2 diabetes mellitus & 18 & 2.3 & & \\
Hypertension & 277 & 35.2 & & \\
CVD & 109 & 13.9 & & \\
Osteoporosis & 50 & 6.4 & & \\
Cancer & 58 & 7.4 & & \\
Deaths & 29 & 3.7 & & \\
\hline
\end{tabular}

Study population: number of patients, mean values (mean), standard deviation (STD), minimum (Min), maximum (Max), the difference will be the range, cerebrovascular disease (CVD)

There are statistical differences between men and women in weight, BMI, Follow-up, Smokerstatus, Typ 2 diabetes, hypertension, osteoporosis No differences were detected in age, cerebrovascular disease, cancer and deaths

(HR, 3.01; 95\% CI, 1.30-6.98; $P=0.01$ ). A previous cerebrovascular incident resulted in a higher mortality risk (HR, 2.48; 95\% CI, 1.45-4.25; $P=0.01$ ). The bivariate calculated hazard ratio of mortality was $1.96(95 \%$ CI, 1.21-3.19, $P=0.01$ ) for hypertensive participants compared with non-hypertensive subjects. Active smokers did not have a significantly higher mortality rate than non-smokers. Participants who reported being diagnosed with cancer during the 6-year period before inclusion in the cohort did not have a higher mortality risk than those without a cancer diagnosis. For cancer, the follow-up time was 3.58 years (min. 0.26 years; max. 4.55 years). We obtained the same finding with respect to heart disease. In fact, we observed no higher mortality risk for any of the above conditions (Table 3).

Table 3 Primary risk factors and assignment as cause of death $(n=1467)$

\begin{tabular}{llll}
\hline Risk Factor & Hazard Ratio & $p$ & $95 \% \mathrm{Cl}$ \\
\hline Smoking & 1.06 & 0.90 & $0.43-2.65$ \\
Hypertension & 1.96 & 0.01 & $1.21-3.19$ \\
Cancer & 1.59 & 0.25 & $0.73-3.49$ \\
Cerebrovasc. Disease & 2.48 & 0.01 & $1.45-4.25$ \\
Heart Disease & 2.04 & 0.13 & $0.82-5.08$ \\
Type 2 diabetes & 2.79 & 0.01 & $1.38-5.66$ \\
Osteoporosis & 3.01 & 0.01 & $1.30-6.98$ \\
\hline
\end{tabular}

Binary variables (smoking, hypertension, cancer, cerebrovascular disease, type 2 diabetes mellitus, osteoporosis) are given as hazard ratio's. 95\% Cl: 95\% Confidence Interval 


\section{Multivariate analysis}

The results of the multivariate analysis using the Cox proportional hazard model are shown in Table 4. Diabetes was a stable risk factor with a HR of 2.17. A slight confounding effect was evident in the bivariate analysis. Our model demonstrated that osteoporosis was a risk factor for mortality, although it was underestimated in the bivariate analysis ( $\mathrm{HR}, 4.46)$. Other important factors that influenced mortality were hypertension (OR, 1.81), age (HR, 1.10), and female sex (HR, 0.48).

\section{Survival analysis}

Survival analysis obtained by the Kaplan Meier Method showed a statistical reduced life expectancy in patients having osteoporosis (see Fig. 3).

\section{Influence of a low BMI and vitamin D3 serum level on osteoporosis}

Of the participants diagnosed with osteoporosis, 20.7\% had a BMI lower than $21 \mathrm{~kg} / \mathrm{m}^{2}$ compared with $9.8 \%$ in the non-osteoporotic sub-cohort $\left(P<0.01, \mathrm{Chi}^{2}\right)$. A 25hydroxvitamin D3 serum level $<13 \mathrm{ng} / \mathrm{mL}$ was observed in $3.8 \%$ of the subjects in the osteoporotic sub-cohort compared with $15.8 \%$ in those without an osteoporosis diagnosis $\left(P<0.02, \mathrm{Chi}^{2}\right)$. (see Fig. 4$)$.

\section{Discussion}

This report describes mortality and associated risk factors in an older Swiss population. Beyond the effects of these risk factors on mortality, a central concern is the time lag between their identification and the occurrence of death. As of March 2017, 1401 study participants survived, and 66 had died. Fortunately, that number is relatively low; however, these data allow us to employ health risk management techniques when assessing the potential causes of death for target prevention.

In addition to T2DM, osteoporosis was a strong predictor of mortality in our senior cohort. This finding was evident in the bivariate analysis (Table 3 ) and our survival analysis. In our multivariate model using Cox regression models with covariates (Table 4), osteoporosis had a

Table 4 Cox proportional hazards model for mortality

\begin{tabular}{llll}
\hline Risk Factor & Hazard Ratio & $p$ & $95 \% \mathrm{Cl}$ \\
\hline Hypertension & 1.81 & 0.02 & $1.09-3.03$ \\
Type 2 diabetes & 2.17 & 0.04 & $1.04-4.52$ \\
Osteoporosis & 4.46 & 0.01 & $1.82-10.91$ \\
Age & 1.10 & 0.01 & $1.04-1.17$ \\
Age*Age & 1.003 & 0.04 & $1.001-1.006$ \\
Female Gender & 0.48 & 0.01 & $0.28-0.81$ \\
\hline $\begin{array}{l}\text { Age*Age: Age has a square function in the model. 95\% Cl: 95\% } \\
\text { Confidence Interval }\end{array}$ & \\
$\begin{array}{l}\text { Type } 2 \text { diabetes, hypertension, osteoporosis, age, and female sex were } \\
\text { important predictors in the model with death as the outcome variable }\end{array}$
\end{tabular}

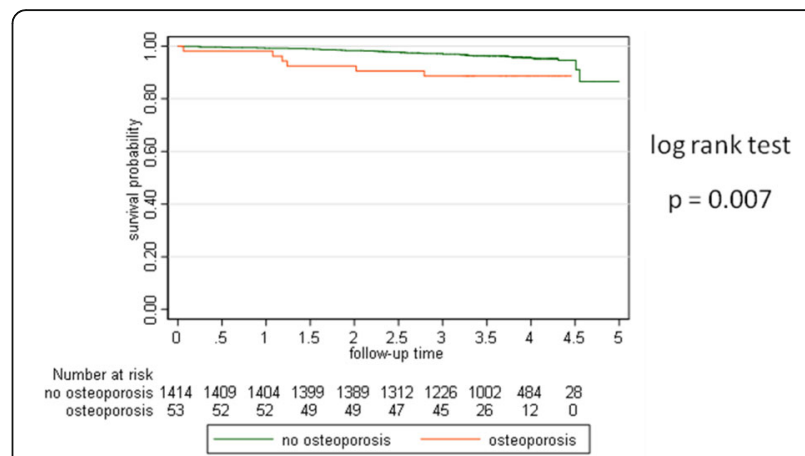

Fig. 3 Kaplan Meier curves show a statistical significant difference. Mean Follow up time was 3.68 years (95\% Cl 3.64-3.71 years)

higher relative risk of mortality than type 2 diabetes. The relative risk of osteoporosis seems to be high. Based on the absolute numbers, we assumed that osteoporosis in our cohort was responsible for approximately 6\% of deaths; hypertension was responsible for $26 \%$ of deaths and diabetes was responsible for $9 \%$ of all fatalities. Although comparisons with other mortality risk factors in a cohort of healthy senior citizens are lacking, osteoporosis has been identified in several studies as an important risk factor for all-cause mortality. Our data confirmed the results of a Danish cohort study, which found a shorter life expectancy among osteoporosis patients. One conclusion of the present study was significant comorbidity in such patients with a higher mortality risk [14]. Additional evidence for osteoporosis as an important all-cause mortality risk factor comes from studies in the Netherlands [15], United Kingdom [17], and Austria [18]; however, those studies were conducted retrospectively. In addition, the

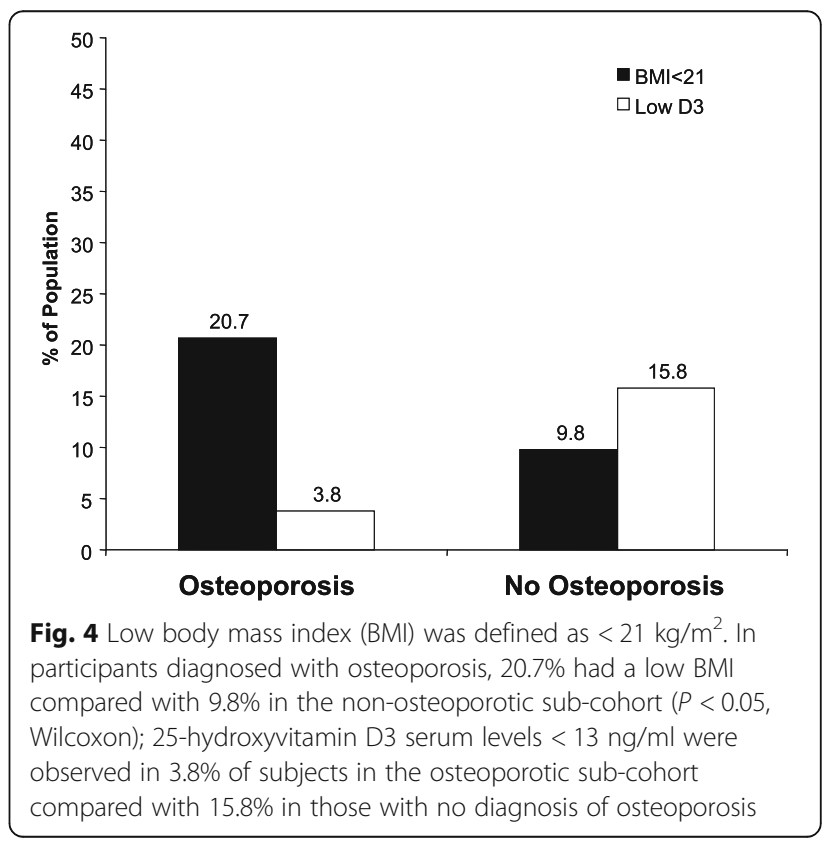


relatively low prevalence of osteoporosis in our cohort compared to that in the general Swedish population in the same age group (osteoporosis prevalence rates of $7.8 \%$ in men and $27.9 \%$ in women) would predict a much higher death rate and most likely a higher public health relevance than was found in our study. Based on our results, we propose that osteoporosis is relevantly underreported in the study population, which may lead to an underestimation of its public health relevance compared to diseases such as hypertension.

Why might osteoporosis lead to a higher mortality rate? The mechanism is complex and multifactorial, and the precise pathways are not known. As shown by Sakem and coworkers, a low vitamin D level is involved in an altered immune response [13]. However, we found no direct association between vitamin $\mathrm{D}$ and all-cause mortality and osteoporosis; specifically, $3.8 \%$ of osteoporosis patients had high vitamin D levels, whereas 15 . $8 \%$ of patients without osteoporosis had a vitamin D level of less than $13 \mathrm{ng} / \mathrm{mL}$ (Fig. 4). In contrast to the results for 25-hydroxyvitamin D3 levels, 20.7\% of our participants with low BMIs (defined as less than $21 \mathrm{~kg} / \mathrm{m}^{2}$ ) were in the osteoporotic group compared with only $9.8 \%$ in the non-osteoporotic population. This result indicates that an impaired nutritional state could be reflected by osteoporosis. This finding supports the results of a US study by Thomas-John et al., which reported that osteoporosis was associated with weight loss and low consumption of dairy products, suggesting that malnutrition might be an important cofactor [19]. In addition, an Australian longitudinal study observed a clinically relevant reduction in mortality among older seniors diagnosed with osteoporosis without fractures undergoing bisphosphonate treatment [20].

The most prevalent contemporary causes of death are cardiovascular and cerebrovascular disorders and cancer. Recent decades have seen rapid advances in diagnoses and surgical and pharmaceutical therapies for these conditions. Comparative studies of mortality in Europe have shown that the all-cause mortality per 1000 people aged 70-74 years is 25.1 for women and 47.1 for men [21]. The all-cause mortality rates in Alaska and Florida were estimated to be 43.5 and 44.2, respectively. In our cohort (mean age, 72.1 years; 95\% CI, 71.7-72.5), the overall mortality was 12.2 per 1000 . In the present study of an apparently healthy Swiss population of pensioners, we found that T2DM, osteoporosis, and hypertension were important risk factors for mortality.

Unsurprisingly, hypertension and T2DM are leading causes of mortality, as shown by the Cardiovascular Health Study [3]. The prevalence of T2DM is greatest in people over 65 years of age, and the highest incidence also occurs in that age group [22-24]. Some authors believe that the burden of diabetes in the older generation will increase further due to demographic changes, the rising incidence of T2DM in all groups [22], and the longer survival times of people diagnosed with diabetes at a younger age [25]. However, older people are underrepresented in clinical trials; thus, they are often treated according to guidelines based on expert opinions and extrapolation of results obtained from trials on younger people [26]. People diagnosed with T2DM at an older age account for approximately half of all new cases. Consequently, diabetes and mortality data in older populations have produced heterogenic results and have led to a mortality risk estimation with an OR of 3.0 [27] but only a slight, non-significant risk elevation [28]. One systematic review demonstrated a pooled OR of 1.4 for mortality and T2DM in an elderly population over 65 years of age [29]. Our data from this population-based prospective cohort indicate that T2DM is a major risk factor for death, even for the older generation. Diabetes appears to be a leading cause of arteriosclerosis and death, even with the relatively short follow-up period of 3.7 years used by this study.

In addition to diabetes, hypertension is an independent predictor of mortality in elderly populations. This result is not surprising and has been convincingly demonstrated by multiple studies [30-32]. The magnitude of its effect is associated with the degree of hypertension [26]. Weidung et al. showed that mortality due to hypertension increased in older adults who were active and robust [27]. We assumed that the individuals in our cohort were robust, since being subjectively healthy was a requirement for inclusion in the study. Huynh et al. found that hypertension was less of a risk factor for allcause mortality than T2DM. In their models obtained from a cohort of older adults, T2DM was responsible for $50 \%$ of cardiovascular mortality, although it may have overlapped with the effect of hypertension [33]. A similar magnitude of mortality risk was reported in the multivariate models of Fried et al. in the Cardiovascular Health Study [3].

We did not find that a history of cancer was a predictor of death. That result was expected, since the observational time was too short to demonstrate an effect of cancer on all-cause mortality. In this context, comorbidities other than cancer play more important roles in all-cause mortality in older patients diagnosed with cancer, at least in cases with a relatively short surveillance period [34], such as the present interim report.

One strength of the present study is its prospective design and follow-up of 3.7 years in subjectively healthy seniors. A weakness is the lack of osteodensitometry measurements to define the disease. Additionally, our data are based on self-reporting and may have underestimated conditions. On the other hand, in the absence of other representative samples, this study provides the best 
available estimates, as stated elsewhere [35]. Thus, our results may have overestimated the association between osteoporosis and mortality in this older population as a result of recall bias. Osteoporosis and malnutrition may be easily treated, but they have large impacts on public health. We believe that osteoporosis in the elderly may be under-diagnosed as a result of reduced physician awareness of the condition. Moreover, our population showed a smaller prevalence of osteoporosis than the reported prevalence in Sweden (women, CH: 6.4\%; women SWE: 27.9\%). This finding suggests underreporting in our sample. Diagnosing osteoporosis should be undertaken more proactively in older people with subjectively good health.

\section{Conclusions}

We demonstrated that hypertension and T2DM followed by osteoporosis were major factors of all-cause mortality in subjectively healthy seniors. Osteoporosis is probably underestimated due to underreporting and underestimation by clinicians. Osteoporosis should be more actively diagnosed in healthy older people before they experience osteoporosis-associated incidents.

\section{Abbreviations}

BMI: Body mass index; Cl: Confidence interval; Fig.: Figure; FPG: Fasting plasma glucose; HbA1c: Haemoglobin A1c; OR: Odds ratio; T2DM: Type 2 diabetes mellitus

\section{Acknowledgements}

The authors thank Kurt Lippuner and Andreas Popp, Department of Osteoporosis, Bern University Hospital and University of Bern, for their important comments and critical review of the manuscript.

\section{Funding}

This work is funded by an unrestricted grant from the INOVA Research Foundation (Forschungs- und Förderstiftung INOVA), Principality of Liechtenstein. The funding body had no role in the design of the study, collection, analysis and interpretation of data, writing the manuscript and decision to submit for publication.

\section{Availability of data and materials}

The datasets used and/or analysed during the current study are available from the corresponding author upon reasonable request.

\section{Transparency}

The lead authors affirm that the manuscript is an honest, accurate, and transparent account of the study being reported, that no important aspects of the study have been omitted, and that any discrepancies from the study as planned have been explained.

\section{Authors' contributions}

JPG, ZS and LR contributed essentially to the conception of the idea of the study. JPG, UEN, ZS, LR and MR designed the study. JPG and JPR analysed the data. JPG, JPR, ZS, and UEN interpreted the data. JPG wrote the first draft of the manuscript, which was revised by all authors. ZS revised it critically for important intellectual content. All authors approved the final version of the submitted manuscript. All authors had full access to all of the data (including statistical reports and tables) in the study and take responsibility for the integrity of the data and the accuracy of the data analysis. JPG is a guarantor.

\section{Ethics approval and consent to participate}

Ethical approval for the present study was obtained from the Cantonal Ethics Committee of Bern (KEK Bern, Study Nr 166/08), Bern, Switzerland.
Written informed consent was obtained from all participants prior to the baseline assessments.

\section{Competing interests}

The authors declare that they have no competing interests.

\section{Publisher's Note}

Springer Nature remains neutral with regard to jurisdictional claims in published maps and institutional affiliations.

\section{Author details}

${ }^{1}$ Magendarm Thalwil AG, Zürcherstrasse 61, CH-8800 Thalwil, Switzerland. ${ }^{2}$ Department of Diabetes, Endocrinology, Nutritional Medicine and Metabolism, Bern University Hospital and University of Bern, Bern, Switzerland. ${ }^{3}$ Divisions of Clinical Chemistry and Haematology, Labormedizinisches Zentrum Dr. Risch, Waldeggstrasse, Liebefeld b, Bern, Switzerland. ${ }^{4}$ Central Laboratory, Kantonsspital Graubünden, Loëstrasse, 170 Chur, Switzerland. ${ }^{5}$ University of Basel, Klingelbergstrasse 61, 4056 Basel, Switzerland. ${ }^{6}$ Department of General Internal Medicine, Bern University Hospital and University of Bern, Bern, Switzerland. 'Labormedizinisches

Zentrum Dr. Risch, Landstrasse, Schaan, Liechtenstein.

Received: 23 June 2017 Accepted: 7 May 2018

Published online: 15 May 2018

References

1. Panorama. Swiss Federal Office of Statistics. February 2016 FSO do-d-00.01pan-01.

2. Morley K. Daily telegraph July 31th 2015.

3. Fried LP, Kronmal RA, Newman AB, Bild DE, Mittelmark MB, Polak JF, Robbins JA, Gardin JM. Risk factors for 5-year mortality in older adults. The cardiovascular health study. JAMA. 1998;279:585-92.

4. Kanis JA, McCloskey EV, Johansson $\mathrm{H}$, et al. European guidance for the diagnosis and management of osteoporosis in postmenopausal women. Osteoporos Int. 2013;24:23-57.

5. Lippuner K, Grifone S, Schwenkglenks M, Schwab P, Popp AW, Senn C, Perrelet R. Comparative trends in hospitalizations for osteoporotic fractures and other frequent diseases between 2000 and 2008. Osteoporos Int. 2012; 23(3):829-39.

6. Cooper C, Atkinson EJ, Jacobsen SJ, O'Fallon M, Melton L III. Populationbased study of survival after osteoporotic fractures. Am J Epidemiol. 1993; 137:1001-5.

7. Briot K, Cortet B, Thomas T, Audran M, Blain H, Breuil V, Chapuis L, Chapurlat R, Fardellone P, Feron JM, Gauvain JB, Guggenbuhl P, Kolta S, Lespessailles E, Letombe B, Marcelli C, Orcel P, Seret P, Trémollières F, Roux C. 2012 update of French guidelines for the pharmacological treatment of postmenopausal osteoporosis. Joint Bone Spine. 2012;79:304-13.

8. Mussolino ME, Madans JH, Gillum RF. Bone mineral density and mortality in women and men: the NHANES I epidemiologic follow-up study. Ann Epidemiol. 2003;13:692-7.

9. Van Der Klift M, Pols HA, Geleijnse JM, Van Der Kuip DA, Hofman A, De Laet CE. Bone mineral density and mortality in elderly men and women: the Rotterdam Study. Bone. 2002;30:643-8.

10. Suzuki T, Yoshida H. Low bone mineral density at femoral neck is a predictor of increased mortality in elderly Japanese women. Osteoporos Int. 2010;21:71-9.

11. Svedbom A, Ivergard M, Hernlund E, Rizzoli R, Kanis JA. Epidemiology and economic burden of osteoporosis in Switzerland. Arch Osteoporos. 2014;9:187.

12. Hernlund E, Svedbom A, Ivergård M, Compston J, Cooper C, Stenmark J, EV MC, Jönsson B, Kanis JA. Osteoporosis in the European Union: medical management, epidemiology and economic burden. A report prepared in collaboration with the international osteoporosis foundation (IOF) and the European Federation of Pharmaceutical Industry Associations (EFPIA). Arch Osteoporos. 2013;8:136.

13. Escobar M, Moser M, Risch L, Risch M, Nydegger UE, Stanga Z. Impaired glucose metabolism and type 2 diabetes in apparently healthy senior citizens. Swiss Med Wkly. 2015;145:w14209. https://doi.org/10.4414/smw. 2015.14209 eCollection 2015

14. Abrahamsen B, Osmond C, Cooper C. Life expectancy in patients treated for osteoporosis: Obervational cohort study using National Danish Prescription Data. J Bone Miner Res. 2015;30(9):1553-9. 
15. Buckens CF, van der Graaf $Y$, Verkooijen HM, Mali WP, Isgum I, Mol CP, Verhaar $H J$, Vliegenthart R, Oudkerk M, van Aalst CM, de Koning HJ, de Jong PA. Osteoporosis markers on low-dose lung cancer screening chest computed tomography scans predict all-cause mortality. Eur Radiol. 2015;25:132-9.

16. Risch M, Nydegger U, Risch L. SENIORLAB: a prospective observational study investigating laboratory parameters and their reference intervals in the elderly. Medicine (Baltimore). 2017;96(1):e5726. https://doi.org/10.1097/MD 0000000000005726

17. Klop C, Welsing PMJ, Cooper C, Harvey NC, Elders PJM, Bijlsmas JWJ, Leufkens HGM, de Vries F. Mortality in British hip fracture patients, 2000-2010: a population-based retrospective cohort study. Bone. 2014; $66: 171-7$

18. Brozek W, Reichardt B, Kimberger O, Zwerina J, Dimai HP, Kritsch D, Klaushofer K, Zwettler E. Mortality after hip fracture in Austria 2008-2011. Calcif Tissue Int. 2014;95:257-66.

19. Thomas-John M, Codd MB, Manne S, Watts NB, Mongey AB. Risk factors for the development of osteoporosis and osteoporotic fractures among older men. J Rheumatol. 2009;36:1947-52.

20. Center JR, Bliuc D, Nguyen ND, Nguyen TV, Eisman JA. Osteoporosis medication and reduced mortality risk in elderly women and men. J Clin Endocrinol Metab. 2011;96(4):1006-14.

21. Warnes AM. Cause-Specific Late-Age Mortality Rates as Indicators for Public Health Priorities. In: Espace, populations, sociéteés, 2000-3. Le vieillissement dans le monde. pp.437-450.

22. Wild S, Sicree R, Roglic G, King H, Green A. Global prevalence of diabetes: estimates for the year 2000 and projections for 2030. Diabetes Care. 2004; 27:1047-53.

23. Ubink-Veltmaat LJ, Bilo HJG, Groenier KH, Houweling ST, Rischen RO, Meyboom-de Jong B. Prevalence, Incidence and mortality of type 2 diabetes mellitus revisited: a prospective population-based study in the Netherlands (ZODIAC-1). Eur J Epidemiol. 2003;18:793-800.

24. McBean M, Gilbertson D, Li S, Collins A. Differences in diabetes prevalence, incidence and mortality among the elderly of four racial/ ethnic groups: whites, blacks, Hispanics, and Asians. Diabetes Care 2004;27:2317-24.

25. Wilson P, Anderson K, Kannel W. Epidemiology of diabetes mellitus in the elderly. The Framingham study Am J Med. 1986;80(Suppl. 5a):3-9.

26. Lee $P$, Alexander KP, Hammill BG, Peterson ED. Representation of elderly persons and women in published randomized trials of acute coronary syndromes. JAMA. 2001;286:708-13.

27. Croxson SCM, Price DE, Burden M, Jagger C, Burden AC. The mortality of elderly people with diabetes. Diabet Med. 1994;11:250-2.

28. Kuller LH, Velentgas P, Barzilay J, Beauchamp NJ, O'Leary DH, Savage PJ. Diabetes mellitus subclinical cardiovascular disease and risk of incident cardiovascular disease and all-cause mortality. Arterioscler Thromb Vasc Biol. 2000;20:823-9.

29. Barnett KN, McMurdo MET, Ogston SA, Morris AD, Evans JMM. Mortality in people diagnosed with type 2 diabetes at an older age: a systemic review. Age Ageing. 2006;35:463-8.

30. Wu CY, Hu HH, Chou YJ, Huang N, Chou YC, Li CP. High blood pressure and all-cause and cardiovascular disease mortalities in community-dwelling older adults. Medicine (Baltimore). 2015;94(47):e2160. https://doi.org/10. 1097/MD.0000000000002160

31. Weidung B, Boström G, Toots A, Nordström P, Carlberg B, Gustafson Y, Littbrand $\mathrm{H}$. Blood pressure, gait speed, and mortality in very old individuals: a population-based cohort study. J Am Med Dir Assoc. 2015;16(3):208-14.

32. Williamson JD, Supiano MA, Applegate WB, Berlowitz DR, Campbell RC, Chertow GM, Fine LJ, Haley WE, Hawfield AT, Ix JH, Kitzman DW, Kostis JB, Krousel-Wood MA, Launer LJ, Oparil S, Rodriguez CJ, Roumie CL, Shorr Rl, Sink KM, Wadley VG, Whelton PK, Whittle J, Woolard NF, Wright JT Jr, Pajewski NM, SPRINT research group. Intensive vs standard blood pressure control and cardiovascular disease outcomes in adults aged $\geq 75$ years: a randomized clinical trial. JAMA. 2016;315(24):2673-82. https://doi.org/10. 1001/jama.2016.7050.

33. Huynh QL, Reid CM, Chowdhury EK, Huq MM, Billah B, Wing LM, Tonkin AM, Simons LA. Nelson MR; second Australian National Blood Pressure Management Committee. Prediction of cardiovascular and all-cause mortality at 10 years in the hypertensive aged population. Am J Hypertens. 2015;28(5):649-56.

34. Jordan JH, Thwin SS, Lash TL, Buist DS, Field TS, Haque R, Pawloski PA, Petersen HV, Prout MN, Quinn VP, Yood MU, Silliman RA, Geiger AM.
Incident comorbidities and all-cause mortality among 5-year survivors of stage I and || breast cancer diagnosed at age 65 or older: a prospectivematched cohort study. Breast Cancer Res Treat. 2014;146(2):401-9.

35. D E, Paccaud F, Vollenweider $P$, Marques-Vidal $P$. Trends in self-reported prevalence and management of hypertension, hypercholesterolemia and diabetes in Swiss adults, 1997-2007. BMC Public Health. 2011;11:114.

\section{Ready to submit your research? Choose BMC and benefit from:}

- fast, convenient online submission

- thorough peer review by experienced researchers in your field

- rapid publication on acceptance

- support for research data, including large and complex data types

- gold Open Access which fosters wider collaboration and increased citations

- maximum visibility for your research: over $100 \mathrm{M}$ website views per year

At BMC, research is always in progress.

Learn more biomedcentral.com/submissions 